\title{
Combined efficacy of biologically synthesized silver nanoparticles and different antibiotics against multidrug-resistant bacteria
}

This article was published in the following Dove Press journal:

International Journal of Nanomedicine

19 August 2013

Number of times this article has been viewed

Syed Zeeshan Haider Naqvi

Urooj Kiran

Muhammad Ishtiaq Ali

Asif Jamal

Abdul Hameed

Safia Ahmed

Naeem Ali

Microbiology Research Laboratory, Department of Microbiology, Faculty of Biological Sciences, Quaid-i-Azam University, Islamabad, Pakistan
Correspondence: Naeem Ali

Department of Microbiology, Faculty of Biological Sciences, Quaid-i-Azam University (45320),

Islamabad, Pakistan

Tel +92 5I 90643194

Email naeemali95@gmail.com
Abstract: Biological synthesis of nanoparticles is a growing innovative approach that is relatively cheaper and more environmentally friendly than current physicochemical processes. Among various microorganisms, fungi have been found to be comparatively more efficient in the synthesis of nanomaterials. In this research work, extracellular mycosynthesis of silver nanoparticles (AgNPs) was probed by reacting the precursor salt of silver nitrate $\left(\mathrm{AgNO}_{3}\right)$ with culture filtrate of Aspergillus flavus. Initially, the mycosynthesis was regularly monitored by ultravioletvisible spectroscopy, which showed AgNP peaks of around 400-470 nm. X-ray diffraction spectra revealed peaks of different intensities with respect to angle of diffractions $(2 \theta)$ corresponding to varying configurations of AgNPs. Transmission electron micrographs further confirmed the formation of AgNPs in size ranging from 5-30 nm. Combined and individual antibacterial activities of the five conventional antibiotics and AgNPs were investigated against eight different multidrug-resistant bacterial species using the Kirby-Bauer disk-diffusion method. The decreasing order of antibacterial activity (zone of inhibition in mm) of antibiotics, AgNPs, and their conjugates against bacterial group (average) was; ciprofloxacin $+\operatorname{AgNPs}(23)>$ imipenem + AgNPs (21) $>$ gentamycin $+\operatorname{AgNPs}(19)>$ vancomycin $+\operatorname{AgNPs}(16)>\operatorname{AgNPs}(15)>$ imipenem (14) $>$ trimethoprim $+\operatorname{AgNPs}(14)>$ ciprofloxacin (13) $>$ gentamycin (11) $>$ vancomycin (4) $>$ trimethoprim (0). Overall, the synergistic effect of antibiotics and nanoparticles resulted in a $0.2-7.0$ (average, 2.8) fold-area increase in antibacterial activity, which clearly revealed that nanoparticles can be effectively used in combination with antibiotics in order to improve their efficacy against various pathogenic microbes.

Keywords: mycosynthesis, silver nanoparticles, antibacterial agents, Aspergillus flavus

\section{Introduction}

Nanotechnology is an emerging field of science with immense scope in the disciplines of electronics, nanomedicine, aeronautics, biomaterials and energy, cosmetics, and food. ${ }^{1}$ The nanoparticles of metals like platinum, silver, and gold are widely applicable in diagnostic sensors, as antimicrobials, and as agents in drug and gene delivery. ${ }^{2}$ Currently, there is a growing demand for the devising of environmentally agreeable protocols for the synthesis of nanomaterials that would avoid the hazardous byproducts associated with current physicochemical processes. ${ }^{3,4}$

A striking opportunity of green nanotechnology is to utilize microbial resources for the fabrication of nanoparticles. In the recent past, nanoparticles have been synthesized using various fungi, ${ }^{5-8}$ bacteria, ${ }^{9,10}$ and plants. ${ }^{4,11}$ Bacteria like Bacillus licheniformis, Staphylococcus aureus, and Pseudomonas stutzeri and fungi like Fusarium semitactum, Fusarium oxysporum, Aspergillus sp., Aspergillus flavus, and Aspergillus fumigatus 
have been reported to synthesize silver, gold, platinum, and palladium nanoparticles. ${ }^{5-10,12-15}$ Compared with chemical and physical methods, biological synthesis of nanoparticles has proved to be free of any limitations associated with production of hazardous byproducts, and it is simple and cost effective in nature. ${ }^{16,17}$ Microbiological synthesis can take place either intracellularly ${ }^{7,18}$ or extracellularly. $5,6,8,13,15$ The mechanism underlying the synthesis of silver nanoparticles (AgNPs) by fungi can also be predicted; biosynthesis is basically associated with the reducing mechanism of the cellular components. In this reference involvement, the specific position of reductase enzymes was typically cited., ${ }^{5,14}$ The silver ions were subsequently reduced to AgNPs by enzymes present at the fungal cell surfaces. ${ }^{12,13,19}$ The reduction process was also facilitated by certain extracellular enzymes like naphthoquinones and anthraquinones. For instance, extracellularly, F. oxysporum-mediated nicotinamide adenine dinucleotide phosphate-dependent nitrate reductase and a shuttle quinone were accountable for nanoparticle synthesis. ${ }^{5}$

The growing resistance of pathogenic bacterial strains to traditional antibacterial treatments has encouraged alternate strategies to control infections. ${ }^{20}$ During the past decade, a great potential in nanomedicine has been realized due to effectiveness of various nanoconjugates against pathogenic microbes. One approach to countering bacterial drug resistance is the application of metal composites, especially at nano scale, to control bacterial infections. Several enzymes and mutations in genetic sequences may impede multidrug resistance mechanisms by changing the medicine efflux from the cells, which thereby decreases the vulnerability of bacteria to antibacterial agents. ${ }^{21}$ Therefore, scientists are developing new ways to control resistant pathogens. Advancement in nanotechnology has prompted microbiologists to apply metal nanoparticles as an effective way to control certain pathogenic microbes involved in infectious diseases. ${ }^{7,10,17,22-24}$

Metal nanoparticles of silver, copper, and gold have been found to be active against certain pathogenic bacteria and fungi. ${ }^{23-31}$ Comparatively, AgNPs have been intensely studied owing to their distinct properties such as conductivity, chemical stability, catalytic activity, nonlinear optical behavior, and bactericidal activity. ${ }^{23,24,28,32}$ These properties make them suitable for use as a microbial disinfectant in catheters ${ }^{33}$ and medical textiles. ${ }^{34}$ The production of AgNPs is relatively inexpensive, and the addition of these particles into goods such as plastics, clothing, creams, and soaps increase their market value. ${ }^{31}$ New classes of compounds that include nanoparticle-antibiotic conjugates are undergoing clinical evaluations..$^{20,22,23,26,32,35,36}$ The combination of antibiotics and metal nanoparticles could increase the antibiotics' efficacy against resistant pathogens. ${ }^{35,36}$ Moreover, nanoparticleantibiotic conjugates lower the amount of both agents in the dosage, which reduces noxiousness and increases antimicrobial properties. These conjugates were effective against resistant bacteria. Additionally, due to this conjugation, the concentrations of antibiotics were increased at the place of antibiotic-microbe contact and thus expedited the binding between microbes and antibiotics. ${ }^{22}$

The present research was carried out in response to the significance of biological synthesis of nanoparticles and the implications of their use in controlling pathogenic microbes. AgNP synthesis was evaluated utilizing a fungal strain of A. flavus; these nanoparticles were tested for their antibacterial efficacy individually and in combination with various conventional antibiotics against eight different multidrugresistant bacterial isolates.

\section{Materials and methods Microorganisms}

The fungal species A. flavus (nonaflatoxin-producing strain, as described by Abbas et $\mathrm{al}^{37}$ ) used for the synthesis of nanoparticles, was obtained from the Microbiology Research Laboratory at Quaid-i-Azam University, Islamabad, Pakistan. It was maintained on potato-dextrose agar slants. Stock cultures of the fungus were refreshed by subculturing every 15 days.

Pure cultures of eight different bacterial isolates were also obtained from the Microbiology Research Laboratory at Quaid-i-Azam University; these were previously isolated at the Pakistan Institute of Medical Sciences, Islamabad, Pakistan. Among these multidrug-resistant bacterial strains, Escherichia coli, Pseudomonas aeruginosa, and Enterococcus faecalis were resistant to trimethoprim, vancomycin, and ciprofloxacin; $S$. aureus was resistant to trimethoprim and vancomycin; and Micrococus luteus was resistant to trimethoprim, gentamycin, and vancomycin. Acinetobacter baumanii was found to be resistant to imipenem, trimethoprim, gentamycin, and vancomycin, and Klebsiella pneumoniae and Bacillus spp. were resistant to trimethoprim. Stock cultures were refreshed by subculturing every 15 days on nutrient agar plates and were maintained at $4{ }^{\circ} \mathrm{C}$.

\section{Cultivation of fungal biomass}

The mycogenesis of AgNPs was performed using A. flavus. The fungal biomass was cultivated aerobically in a liquid medium containing malt extract $0.3 \mathrm{~g} / 100 \mathrm{~mL}$, glucose $1.0 \mathrm{~g} / 100 \mathrm{~mL}$, yeast extract $0.3 \mathrm{~g} / 100 \mathrm{~mL}$, and peptone $0.5 \mathrm{~g} / 100 \mathrm{~mL}$. The 
$\mathrm{pH}$ of the medium was initially adjusted to 5.8. The fungal culture was inoculated and then grown at $28^{\circ} \mathrm{C}$ in an orbital shaker at $150 \mathrm{rpm}$. After 96 hours, the fungal biomass was removed by filtration using Whatman filter paper no 1 . The fungal cultural filtrate was later used for nanoparticle synthesis.

\section{Assay for the synthesis of nanoparticles}

About $200 \mathrm{~mL}$ of mycelia-free fungal cultural filtrate containing $0.1 \mathrm{M}$ precursor salt $\mathrm{AgNO}_{3}$ was taken in a $500 \mathrm{~mL}$ Erlenmeyer flask. The flask was incubated in a dark condition at $28^{\circ} \mathrm{C}$ on a shaker at $150 \mathrm{rpm}$ for 96 hours. Positive control (culture filtrate without silver salt) and negative control (only $\mathrm{AgNO}_{3}$ solution) were also run along with the experimental flasks, following the method of Bhainsa and D'Souza. ${ }^{8}$

\section{Characterization of nanoparticles by X-ray diffraction and transmission electron microscopy}

During the assay, approximately $1 \mathrm{~mL}$ of sample was withdrawn from the reaction mixture at 0 hours, 2 hours, 4 hours, 6 hours, 24 hours, 48 hours, 72 hours, and 96 hours. The absorbance of the sample was noticed at 200-800 nm wavelengths by ultraviolet-visible spectrophotometer (Agilent 8453 UV-Vis, Agilent Technologies, Santa Clara, CA, USA). Colloidal suspension from the reaction mixture containing silver was concentrated using ultracentrifugation (centrifuge Model H-251, Kokusan Co, Ltd, Tokyo, Japan) at 12,000 rpm for 20 minutes. After concentrating, the silver powder was thoroughly washed three times by pure ethanol and then by sterile deionized water in order to get clean nanoparticles. The nanoparticles were microcentrifuged (Microfuge $^{\circledR} 18$ Centrifuge, Beckman Coulter, Inc, Brea, CA, USA). Finally, the supernatant was removed and the nanoparticles were dried in an oven overnight; hence, the AgNPs were obtained in powder form.

Drop-coated films of dried sample containing nanoparticles on silica were subjected to X-ray diffraction (XRD) analysis (X'pert PRO XRD, PANalytical BV, Almelo, The Netherlands) operating in transmission mode, at $30 \mathrm{kV}$, $20 \mathrm{~mA}$ with $\mathrm{Cu} \mathrm{K} \alpha$ radiation. The AgNPs film was created on carbon-coated copper transmission electron microscopy (TEM) grids and examined by TEM (JEM-1010, JEOL Ltd, Tokyo, Japan) at an accelerating voltage of $80 \mathrm{kV}$.

\section{Preparation of $\mathrm{AgNP}$ suspension}

An AgNP suspension of 100 ppm was prepared by dissolving $0.1 \mathrm{mg}$ of biologically synthesized AgNPs in $1 \mathrm{~mL}$ autoclaved deionized water. The suspension was sonicated for 20 minutes to avoid deposition of AgNPs.

\section{Antibiotics}

Antibiotics were selected from five groups having a different mode of action, including imipenem (carbapenem), trimethoprim (sulfonamide), gentamycin (aminoglycoside), vancomycin (glycopeptide), and ciprofloxacin (quinolone).

\section{Bacterial susceptibility to antibiotics and AgNPs using the Kirby-Bauer disk-diffusion method}

A disk-diffusion scheme was utilized to assess the antibacterial potential of antibiotics, biologically synthesized AgNPs, and their conjugates against eight different bacteria on Mueller-Hinton agar plates (Becton, Dickinson and Company, Franklin Lakes, NJ, USA). ${ }^{38}$ The inoculum of each bacterium was developed by growing the organism overnight in MullerHinton liquid medium on a shaker incubator (200 rpm) at $37^{\circ} \mathrm{C}$. Turbidity of the culture was maintained by comparing with $0.5 \%$ McFarland standard by diluting with $0.9 \% \mathrm{NaCl}$ solution. Muller-Hinton agar plates were seeded with $1 \mathrm{~mL}$ of inoculum of the test bacterial culture to achieve $10^{6} \mathrm{CFU} / \mathrm{mL}$. A lawn of the test organism was made on autoclaved MullerHinton agar plate using sterile swabs. Plates were allowed to set and then nanoparticle-laden, air-dried sterile discs were placed using sterile forceps. Also, for determining synergistic effects, each standard antibiotic disc was impregnated with $30 \mu \mathrm{L}$ of metallic nanoparticles (100 ppm). Plates were labeled carefully and incubated at $37^{\circ} \mathrm{C}$ for 24 hours to check the activity. Antibacterial activity was expressed as the diameter of the zone of inhibition, measured in millimeters. The assays were implemented in triplicate. Mean values for inhibition zones are presented in Table 1.

\section{Results}

Initially, the extracellular synthesis of AgNPs was observed during incubation of reaction mixture containing culture filtrate of $A$. flavus and silver salt at $30^{\circ} \mathrm{C}$ for 96 hours. The reaction mixture showed a gradual change in coloration from yellow to dark brown (Figure 1A). This change in coloration was not observed in the case of the control flasks (Figure 1B and C). During incubation, the ultraviolet-visible spectroscopy of the reaction mixture showed spectra of increasing intensity (range, 350-600 nm); major peaks were centered around 400-470 nm (Figure 2). The gradual increase in peak areas/absorbance with time was significantly correlated with 


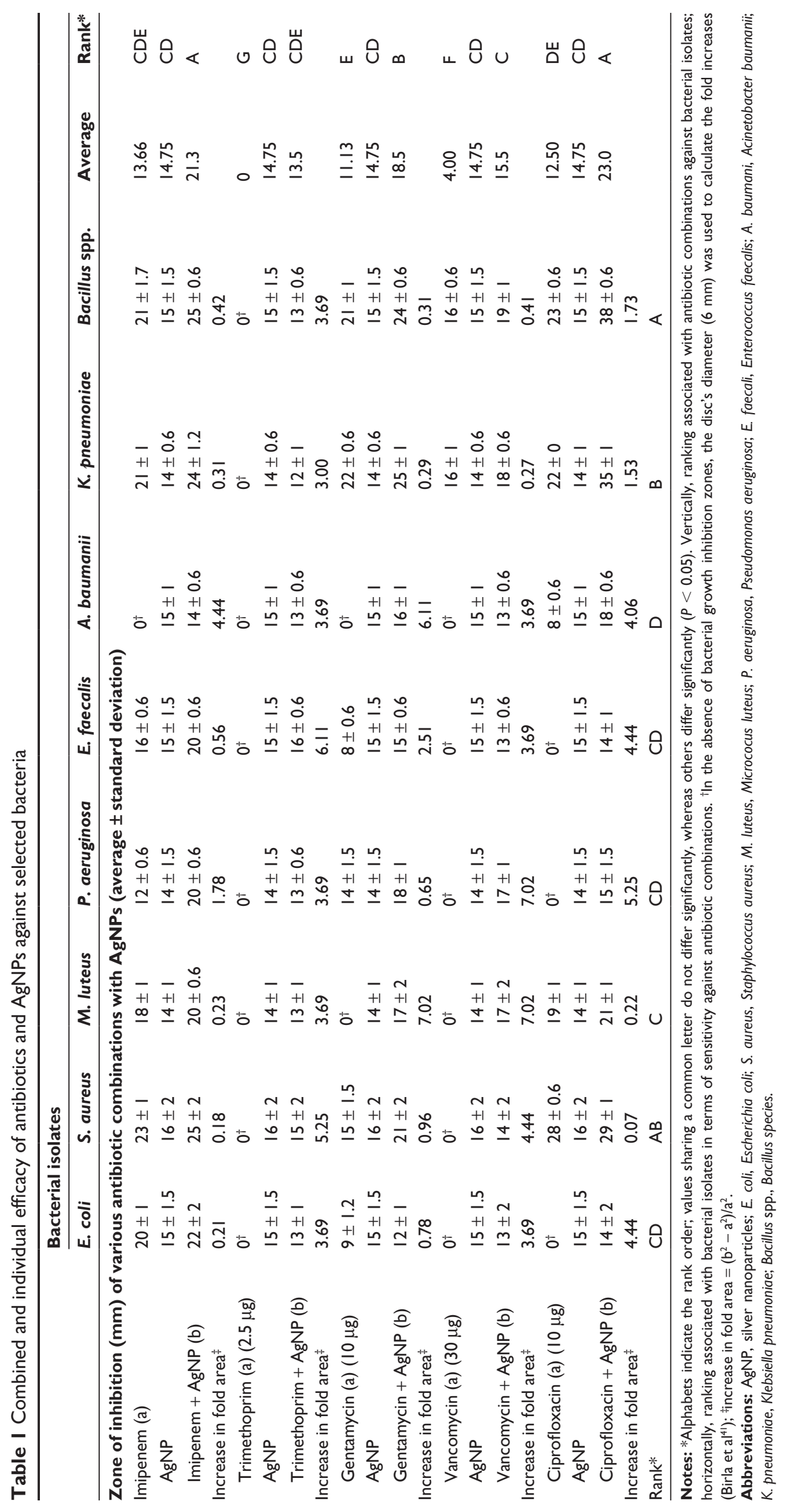




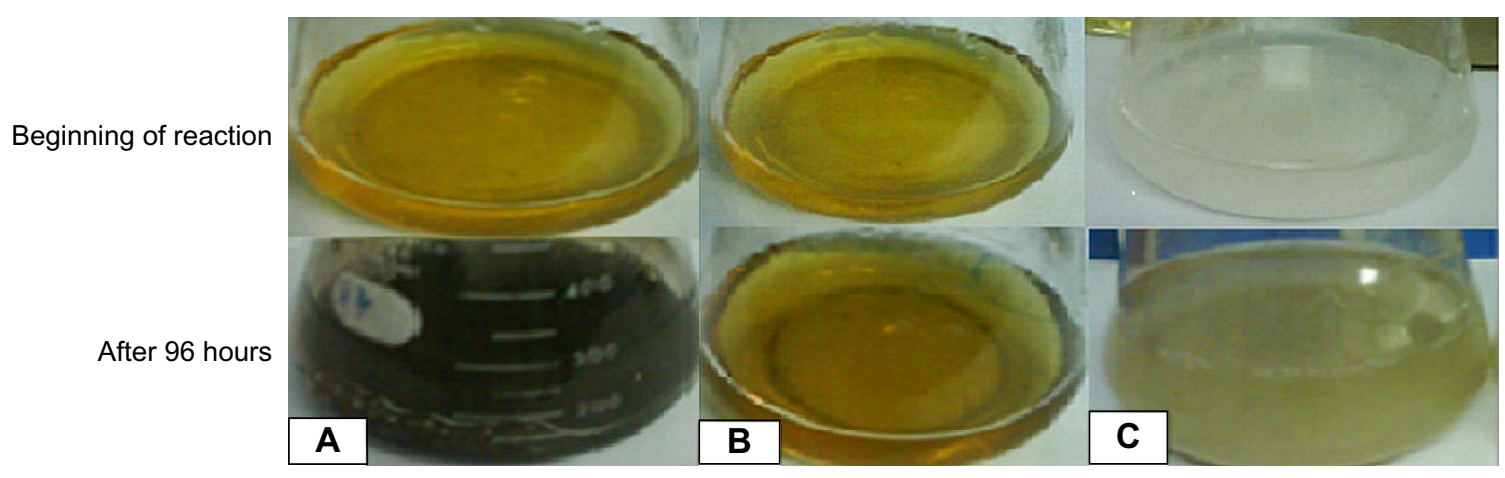

Figure I Extracellular synthesis of AgNPs at the beginning of the reaction and after 96 hours (completion of reaction).

Notes: (A) Culture filtrate: Aspergillus flavus with $\mathrm{AgNO}_{3}$ solution (0.I M). (B) Positive control: filtrate without silver salt. (C) Negative control: sterile deionized water with only $\mathrm{AgNO}_{3}$ solution.

Abbreviation: AgNPs, silver nanoparticles.

change in color of the reaction mixture, indicating nanoparticle synthesis.

XRD and Debye-Scherrer analysis of the drop-coated film of dried sample (reaction mixture) revealed the crystalline nature of nanoparticles (Figure 3). XRD patterns showed four major peaks in the entire spectrum of $2 \theta$ value extending from $20-80$ degrees. The mean size of the crystallites was $13-26 \mathrm{~nm}$ and the size of the silver nanocrystallites was $21 \mathrm{~nm}$ as assessed from the full width at half maximum of the peaks via the DebyeScherrer formulae. TEM micrographs showed nanoparticles with various shapes; however, most were spherical. The size of the particles ranged from 5-30 nm (Figure 4).

\section{Antimicrobial activities}

The efficacy of antibiotics, mycogenized nanoparticles, and their combinations in terms of zones of inhibition (mm) was measured against eight different bacteria (Table 1). The decreasing order of the average antibacterial activity of antibiotics, AgNPs, and their conjugates against bacterial group was observed to be ciprofloxacin $+\mathrm{AgNP}>$ imipenem + AgNP $>$ gentamycin + AgNP $>$ vancomycin + AgNP $>$ AgNP $>$ imipenem $>$ trimethoprim + AgNP $>$ ciprofloxacin $>$ gentamycin $>$ vancomycin $>$ trimethoprim. The average antibacterial activity of the various antibiotics against bacterial group ranged from $0.00-13.66 \mathrm{~mm}$ (zone

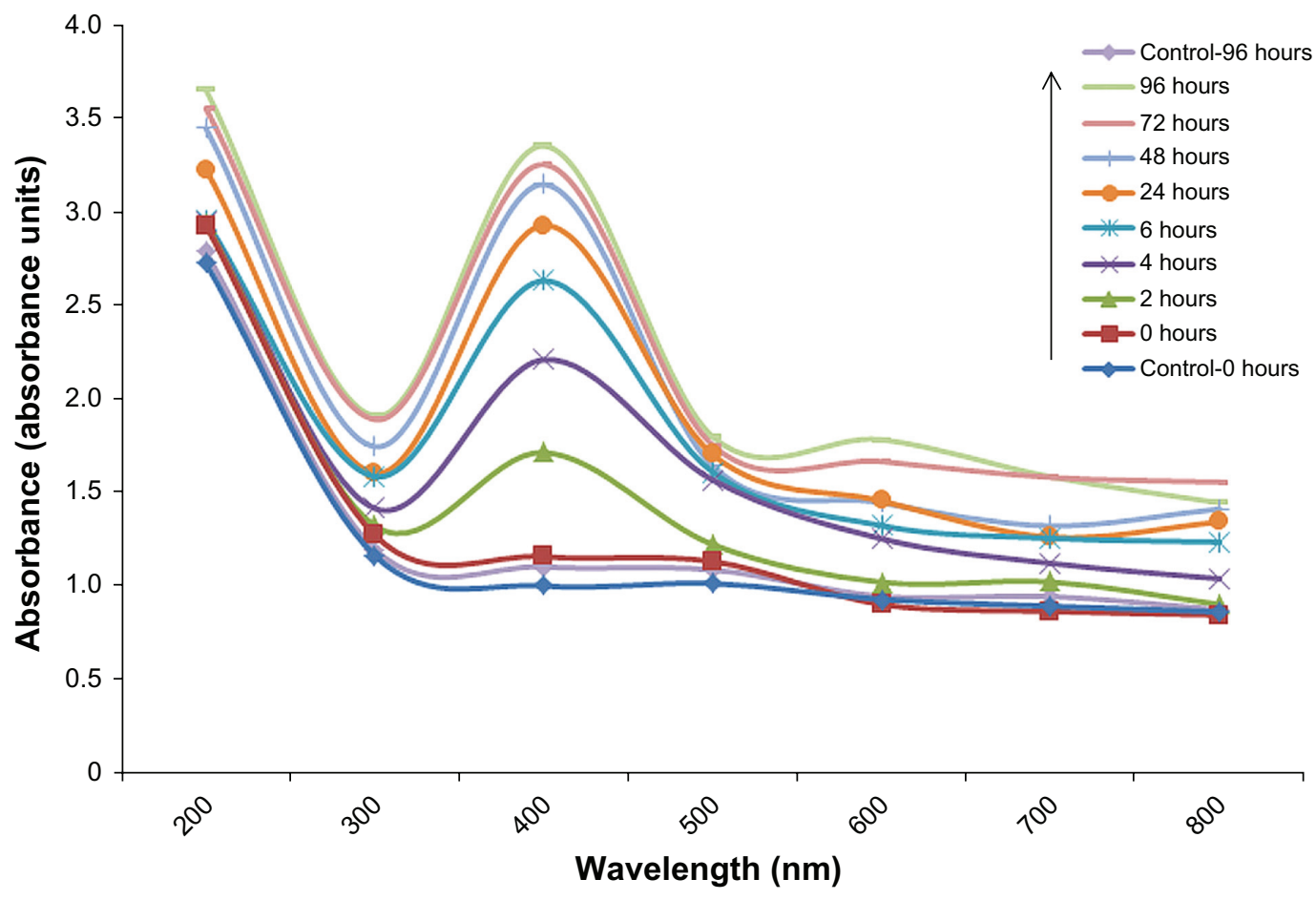

Figure 2 Ultraviolet-visible spectra of aqueous medium containing cell free culture filtrate and silver salt $(0.1 \mathrm{M})$ and of controls over time. 


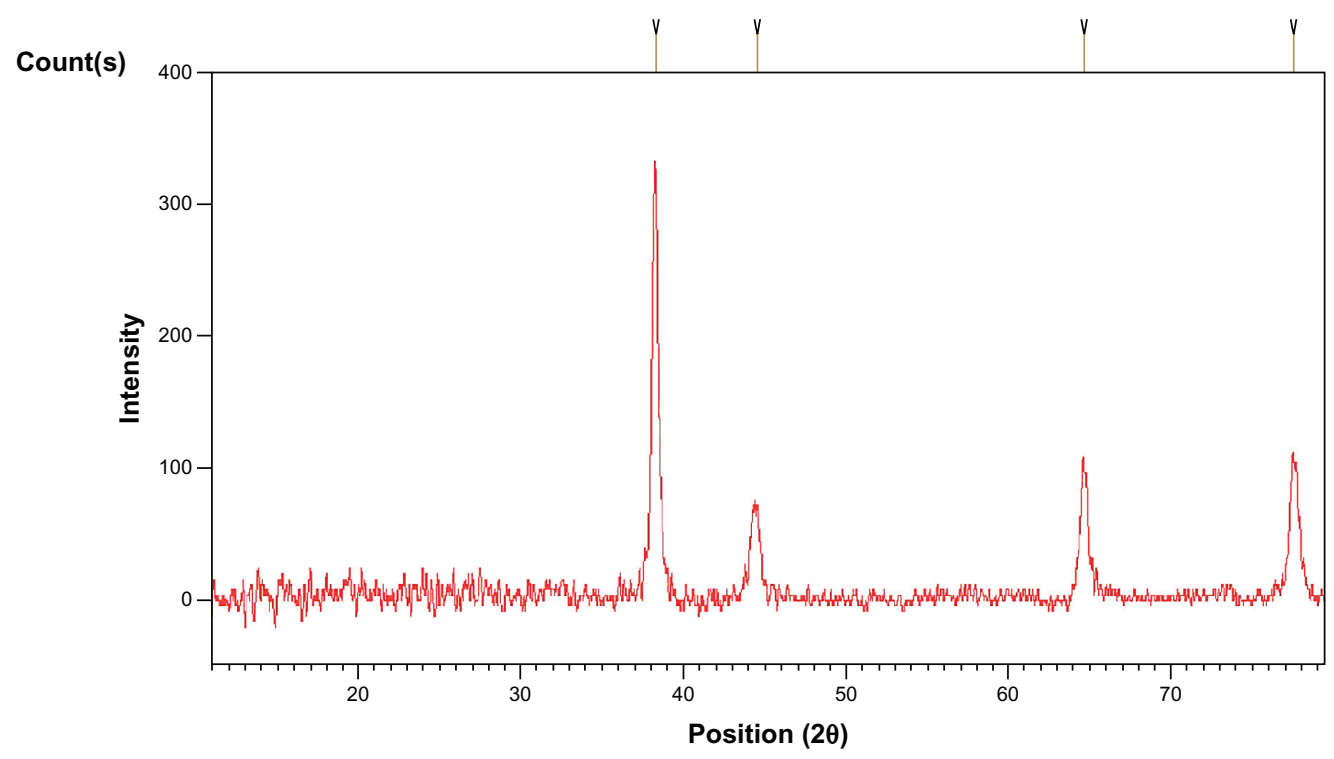

Figure 3 X-ray diffraction pattern of nanoparticle film on copper surface obtained from culture filtrate of Aspergillus flavus.

of inhibition). Specific antibiotic activities were maximum with: imipenem against $S$. aureus $(23 \mathrm{~mm}), K$. pneumoniae (21 mm), Bacillus spp. (21 mm), and E. coli $(20 \mathrm{~mm})$; ciprofloxacin against $S$. aureus $(28 \mathrm{~mm})$, Bacillus spp. (23 $\mathrm{mm})$, and K. pneumoniae $(22 \mathrm{~mm})$; and gentamycin against K. pneumoniae $(22 \mathrm{~mm})$ and Bacillus spp. $(21 \mathrm{~mm})$. All the bacteria except Bacillus spp. and K. pneumoniae were resistant to vancomycin. Similarly, trimethoprim showed no activity against any of the bacterial species.

In the case of AgNPs, mild bactericidal activities were observed in terms of zone of inhibition ranging from 14-16 mm (average, $14.75 \mathrm{~mm}$ ) against bacterial group. Combinations of antibiotics and nanoparticles resulted in average fold-area increases in antibacterial activity (zone

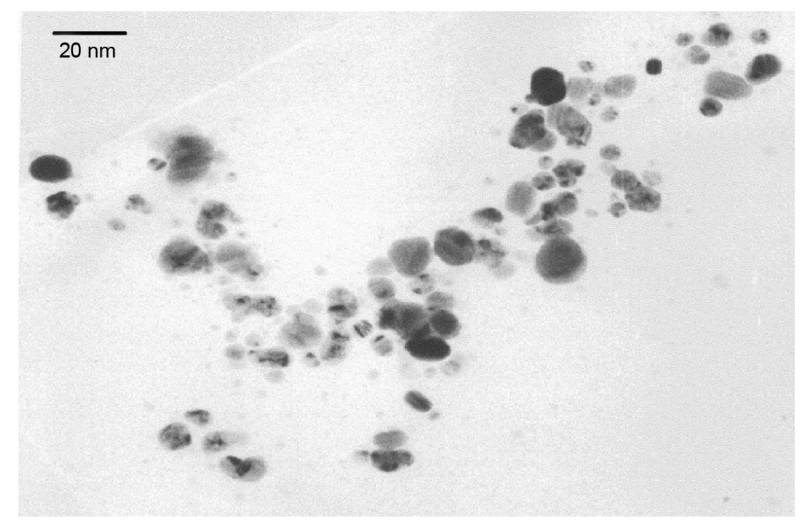

Figure 4 Transmission electron micrograph of AgNPs produced by culture filtrate of Aspergillus flavus.

Abbreviation: AgNPs, silver nanoparticles. of inhibition) of 0.2-4.4 for imipenem + AgNP, 3.0-6.1 for trimethoprim + AgNP, 0.3-7.0 for gentamycin + AgNP, 0.37.0 for vancomycin $+A g N P$, and $0.1-5.3$ for ciprofloxacin + AgNP against bacterial group. Typically, maximum zone(s) of inhibition were observed for $S$. aureus and Bacillus spp. with imipenem $+\operatorname{AgNP}(25 \mathrm{~mm})$, E. faecalis with trimethoprim + AgNP (16 mm), K. pneumoniae with gentamycin + AgNP (25 mm), and Bacillus spp. with vancomycin + AgNP $(19 \mathrm{~mm})$ and with ciprofloxacin $+\operatorname{AgNP}(38 \mathrm{~mm})$.

The tested microbes showed susceptibility in the range of 14-25 mm for imipenem + AgNP conjugate. Trimethoprim + AgNP conjugate exhibited bactericidal activity ranging from $12-16 \mathrm{~mm}$, much better than conventional trimethoprim, which showed no activity against any of the microbes. Gentamycin impregnated with nanoparticles exhibited an efficacy range from $12-25 \mathrm{~mm}$. All the microbes were resistant to vancomycin except $K$. pneumoniae and Bacillus spp., which showed efficacy around $16 \mathrm{~mm}$; when vancomycin-infused nanoparticles were used, a 13-19 mm range was obtained. Ciprofloxacin $+\mathrm{AgNP}$ conjugate showed efficacy against the entire tested microbial community in the 14-38 mm range. Overall, antibacterial combinations of ciprofloxacin and imipenem impregnated with AgNPs showed the maximum efficacy ( $23 \mathrm{~mm}$ and $21 \mathrm{~mm}$, respectively) against the entire tested bacterial community; gentamycin, vancomycin, and trimethoprim infused with AgNPs exhibited efficacies of $19 \mathrm{~mm}, 16 \mathrm{~mm}$, and $14 \mathrm{~mm}$ against bacterial group. The representative zones of inhibition are shown in Figure 5. 


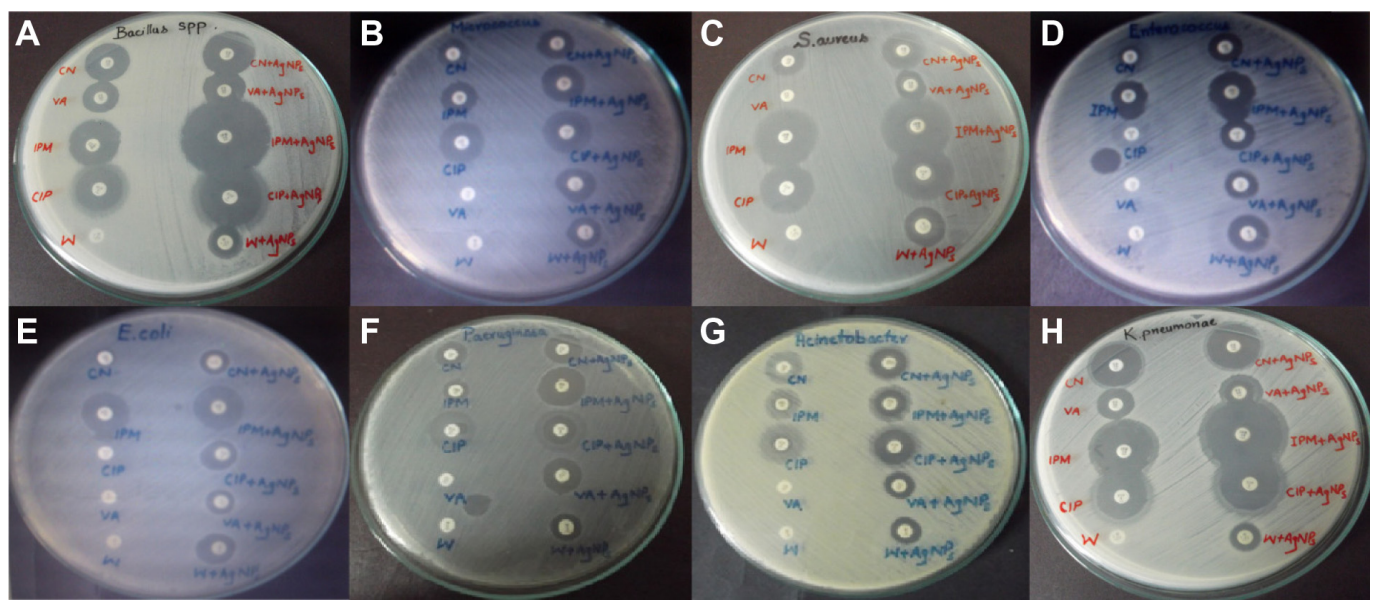

Figure 5 Zones of inhibition of standard antibiotics and AgNPs against multidrug-resistant microorganisms.

Notes: (A) Bacillus; (B) M. luteus; (C) S. aureus; (D) E. faecalis; (E) E. coli; (F) P. aeruginosa; (G) A. baumanii; (H) K. pneumoniae. Abbreviation: AgNPs, silver nanoparticles.

\section{Discussion}

The scope of the present study was based upon exploring the capabilities of fungal strain A. flavus to synthesize AgNPs along with their biomedical application in controlling infectious bacteria. The fungal isolate showed a great deal of capability towards synthesizing AgNPs. In addition, these nanoparticles alone and also in conjugation with various antibiotics proved to be effective in controlling resistant bacteria.

Change in color of the reaction mixture containing salt of $\mathrm{Ag}$ and fungal extract (medium) proved to be the first indication of nanoparticle synthesis. ${ }^{15}$ When the reaction mixture was incubated under dark conditions, the color of the liquid mixture changed from light yellowish brown to dark brown, and than black, subsequently, after 96 hours of reaction. (Figure 1). This change in color of extracellular medium was previously linked with the formation of AgNPs and depicts the excitation of surface plasmon vibrations in the nanoparticles. ${ }^{39,40}$ The change in color intensity (absorbance) was also monitored through ultraviolet-visible spectroscopy. Peaks of the reaction mixture were obtained around $420 \mathrm{~nm}$ (Figure 2). It was reported that the reduction of $\mathrm{Ag}^{+}$to atomic silver $\mathrm{Ag}^{\circ}$ corresponds to absorption at $420 \mathrm{~nm} .{ }^{5,6,8}$ Synthesis of AgNP was previously linked with release of functional proteins in reaction mixture by F. oxysporum, which might have helped reduction of the metal ions into nanoparticles. ${ }^{5}$

Various reports have provided evidence of extracellular generation of AgNPs by XRD and TEM images..$^{5-15}$ Based upon these analytical techniques, extracellular biosynthesis of AgNPs varied from 10-100 nm by Aspergillus niger, ${ }^{15}$ 5-25 $\mathrm{nm}$ by $A$. fumigatus, ${ }^{8}$ and $8-17 \mathrm{~nm}$ by A. flavus under shaking conditions $(150-200 \mathrm{rpm})$ at $25^{\circ} \mathrm{C}-30^{\circ} \mathrm{C} \cdot .^{13,14}$
Similar findings were made in the present study through XRD and TEM, which revealed nanoparticles sized 13-26 nm and 5-30 nm, respectively, by A. flavus under shaking conditions $(150 \mathrm{rpm})$ at $30^{\circ} \mathrm{C}$. Thus, different Aspergillus species were found to be quite capable of synthesizing AgNPs under agitated conditions and specific growth temperatures.

AgNPs have been reported to be an effective bactericidal agent. ${ }^{23,25,30,41-43}$ All of the selected clinical bacterial isolates exhibited resistance against conventional sulfonamide (trimethoprim) and glycopeptide (vancomycin) antibiotics. A synergistic effect of antibiotics (imipenem, gentamycin, vancomycin, and ciprofloxacin) in conjugation with biologically synthesized AgNPs increased the susceptibility among the tested bacteria from $20 \%-35 \%$. The combined effect of AgNPs and antibiotics like imipenem, gentamycin, and ciprofloxacin was notably exhibited against $E$. coli, S. aureus, P. aeruginosa, K. pneumoniae, Bacillus spp., and M. luteus. These results are in line with the findings of Birla et $\mathrm{al},{ }^{41}$ who mentioned increasing efficacies (percentage) of antibiotics like vancomycin, gentamycin, streptomycin, ampicillin, and kanamycin when used in combination with AgNPs against P. aeruginosa, $S$. aureus, and E. coli. In a similar study, ${ }^{35}$ the antimicrobial activities of biologically synthesized AgNPs were assessed with commercially available antibiotics against $\mathrm{G}-$ and $\mathrm{G}+$ bacteria. The antibacterial activities of ampicillin, chloramphenicol, erythromycin, and kanamycin were augmented in the presence of AgNPs. However, highest synergistic effect was observed with ampicillin. Higher dosage for both the AgNPs $(0-40 \mu \mathrm{g} / \mathrm{mL})$ and amoxicillin $(0-0.5 \mathrm{mg} / \mathrm{mL})$ exhibited higher antibacterial effects against $E$. coli in Luria-Bertani medium. When amoxicillin 
impregnated with AgNPs was applied, a superior antibacterial efficiency on $E$. coli cells was obtained than when they were applied separately. Moreover, through dynamic trials/set of experiments it was also found that when this combination was used, the bacterial growth showed reduced and deferred exponential and stationary phases. The higher the number of nanoparticles, the more the bactericidal activity. ${ }^{36}$

The mechanism of action of AgNPs is still not well defined. Many proposed mechanisms about antibacterial effect of silver ions have been presented by researchers. ${ }^{23,25,29,30,35,36,43-45}$ It was hypothesized that nanoparticles form a complex with ampicillin and disrupt peptidoglycan in the cell wall. ${ }^{35}$ Being positively charged, they attack negative charges of transmembrane proteins and can destroy the cell membrane and block the transport channels. ${ }^{44}$ It might be possible that they penetrate inside the bacteria and disrupt cellular activities like transportation, protein synthesis, and nucleic acid functioning. ${ }^{45}$ Likewise, imipenem in combination with positively charged AgNPs both inhibited and disrupted cell-wall synthesis. ${ }^{26}$ It has also been proposed that silver ions penetrate the cell, intercalate themselves between pyrimidine and purine, and denature the DNA molecule. ${ }^{23}$ The antibiotics ciprofloxacin and imipenem in combination with these AgNPs were found to be most effective in inhibiting bacteria: if bacteria develops resistance to one of them, the other bactericidal agent would kill the bacteria. In synergism, the bactericidal effect is enhanced by interaction between active groups like hydroxyl and amino groups present in these antibiotics with AgNPs by chelation. As a result, antibiotic-AgNP conjugate is formed in which an AgNP core is surrounded by antibiotic molecules. Thus, the antimicrobial concentration is increased at the focal site, which leads to increased destruction of bacteria. ${ }^{36}$ More studies need to be conducted to find out the exact mechanism of action to develop a novel antimicrobial drug against multidrug-resistant bacteria.

\section{Conclusion}

In this study, A. flavus was found to be an effective biological tool for the extracellular biosynthesis of stable AgNPs. The antibacterial activity of imipenem, gentamycin, vancomycin, and ciprofloxacin was augmented when impregnated with AgNPs. On the basis of the results from this study, we can deduce that biologically synthesized AgNPs may function by binding to thiol ( $\mathrm{SH}$ ) groups of membrane proteins, enzymes, and phosphate groups of DNA, and can be efficiently used as antimicrobial agents.

\section{Acknowledgments}

The authors are obliged to the Higher Education Commission of the Government of Pakistan for providing financial support under HEC-5000 Indigenous scholarship scheme batch VI.

\section{Disclosure}

The authors report no conflicts of interest in this work.

\section{References}

1. Bhattacharyya D, Singh S, Satnalika N, Khandelwal A, Jeon SH. Nanotechnology, big things from a tiny world: a review. Int $J u$ - and e- Serv, Sci Technol. 2009;2(3):29-38.

2. Bhowmik D, Chiranjib, Chandira RM, Tripathi KK, Kumar KPS. Nanomedicine-an overview. International Journal of PharmTech Research. 2010;2(4):2143-2151.

3. Dahl JA, Maddux BL, Hutchison JE. Toward greener nanosynthesis. Chem Rev. 2007;107(6):2228-2269.

4. Kumar V, Yadav SK. Plant-mediated synthesis of silver and gold nanoparticles and their applications. J Chem Technol Biotechnol. 2009;84(2):151-157.

5. Ahmad A, Mukherjee P, Senapati S, et al. Extracellular biosynthesis of silver nanoparticles using the fungus Fusarium oxysporum. Colloids Surf B Biointerfaces. 2003;28(4):313-318.

6. Basavaraja S, Balaji SD, Lagashetty A, Rajasab AH, Venkataraman A. Extracellular biosynthesis of silver nanoparticles using the fungus Fusarium semitectum. Mater Res Bull. 2008;43(5):1164-1170.

7. Li X, Xu H, Chen Z, Chen G. Biosynthesis of nanoparticles by microorganisms and their applications. J Nanomater. 2011;2011:1-16.

8. Bhainsa KC, D'Souza SF. Extracellular biosynthesis of silver nanoparticles using the fungus Aspergillus fumigatus. Colloids Surf B Biointerfaces. 2006;47(2):160-164.

9. Kalimuthu K, Suresh Babu R, Venkataraman D, Bilal M, Gurunathan S. Biosynthesis of silver nanocrystals by Bacillus licheniformis. Colloids Surf B Biointerfaces. 2008;65(1):150-153.

10. Nanda A, Saravanan M. Biosynthesis of silver nanoparticles from Staphylococcus aureus and its antimicrobial activity against MRSA and MRSE. Nanomedicine. 2009;5(4):452-456.

11. Govindaraju K, Tamilselvan S, Kiruthiga V, Singaravelu G. Biogenic silver nanoparticles by Solanum torvum and their promising antimicrobial activity. Journal of Biopesticides. 2010;3(1 Special Issue):394-399.

12. Zhang X, Yan S, Tyagi RD, Surampalli RY. Synthesis of nanoparticles by microorganisms and their application in enhancing microbiological reaction rates. Chemosphere. 2011;82(4):489-494.

13. Jain N, Bhargava A, Majumdar S, Tarafdar JC, Panwar J. Extracellular biosynthesis and characterization of silver nanoparticles using Aspergillus flavus NJP08: a mechanism perspective. Nanoscale. 2011;3(2): 635-641.

14. Vigneshwaran N, Ashtaputre NM, Varadarajan PV, Nachane RP, Paralikar KM, Balasubramanya RH. Biological synthesis of silver nanoparticles using the fungus Aspergillus flavus. Mater Lett. 2007;61(6):1413-1418.

15. Bhambure R, Bule M, Shaligram N, Kamat M, Singhal R. Extracellular biosynthesis of gold nanoparticles using Aspergillus niger - its characterization and stability. Chemical Engineering and Technology. 2009;32(7):1036-1041.

16. Kim JS, Kuk E, Yu KN, et al. Antimicrobial effects of silver nanoparticles. Nanomedicine. 2007;3(1):95-101.

17. Singh M, Manikandan S, Kumaraguru AK. Nanoparticles: a new technology with wide applications. Research Journal of Nanoscience and Nanotechnology. 2011;1(1):1-11.

18. Sheshadri S, Prakash A, Kowshik M. Biosynthesis of silver nanoparticles by marine bacterium, Idiomarina sp. PR58-8. Bulletin of Materials Science. 2012;35(7):1201-1205. 
19. Mukherjee P, Ahmad A, Mandal D, et al. Fungus-mediated synthesis of silver nanoparticles and their immobilization in the mycelial matrix: a novel biological approach to nanoparticle synthesis. Nano Letters. 2001;1(10):515-519.

20. Kollef MH, Golan Y, Micek ST, Shorr AF, Restrepo MI. Appraising contemporary strategies to combat multidrug resistant gram-negative bacterial infections - proceedings and data from the Gram-Negative Resistance Summit. Clin Infect Dis. 2011;53 Suppl 2:S33-S55; quiz 56.

21. Sibanda T, Okoh AI. The challenges of overcoming antibiotic resistance: plant extracts as potential sources of antimicrobial and resistance modifying agents. African Journal of Biotechnology. 2007;6(25): 2886-2896.

22. Allahverdiyev AM, Kon KV, Abamor ES, Bagirova M, Rafailovich M. Coping with antibiotic resistance: combining nanoparticles with antibiotics and other antimicrobial agents. Expert Rev Anti Infect Ther. 2011;9(11):1035-1052.

23. Rai MK, Deshmukh SD, Ingle AP, Gade AK. Silver nanoparticles: the powerful nanoweapon against multidrug-resistant bacteria. $J \mathrm{Appl}$ Microbiol. 2012;112(5):841-852.

24. Rosarin FS, Mirunalini S. Nobel metallic nanoparticles with novel biomedical properties. Journal of Bioanalysis and Biomedicine. 2011;3(4):85-91.

25. 1. Kim KJ, Sung WS, Moon SK, Choi JS, Kim JG, Lee DG. Antifungal effect of silver nanoparticles on dermatophytes. J Microbiol Biotechnol. 2008;18(8):1482-1484.

26. Sekhon BP. Metalloantibiotics and antibiotic mimics - an overview. J Pharm Educ Res. 2010;1(1):1-20.

27. Sreekanth TVM, Nagajyothi PC, Lee KD. Biosynthesis of gold nanoparticles and their antimicrobial activity and cytotoxicity. $\mathrm{Adv} \mathrm{Sci}$ Lett. 2012;6(7):63-69.

28. Vaidyanathan R, Kalishwaralal K, Gopalram S, Gurunathan S. Nanosilver - the burgeoning therapeutic molecule and its green synthesis. Biotechnol Adv. 2009;27(6):924-937.

29. Yoon KY, Hoon Byeon J, Park JH, Hwang J. Susceptibility constants of Escherichia coli and Bacillus subtilis to silver and copper nanoparticles. Sci Total Environ. 2007;373(2-3):572-575.

30. Lara HH, Ayala-Nuñez NV, Turrent LCI, Padilla CR. Bactericidal effect of silver nanoparticles against multidrug-resistant bacteria. World J Microbiol Biotechnol. 2010;26(4):615-621.

31. Pissuwan D, Niidome T, Cortie MB. The forthcoming applications of gold nanoparticles in drug and gene delivery systems. J Control Release. 2011;149(1):65-71.

32. Roe D, Karandikar B, Bonn-Savage N, Gibbins B, Roullet JB. Antimicrobial surface functionalization of plastic catheters by silver nanoparticles. J Antimicrob Chemother. 2008;61(4):869-876.
33. Durán N, Marcato PD, De Souza GIH, Alves OL, Esposito E. Antibacterial effect of silver nanoparticles produced by fungal process on textile fabrics and their effluent treatment. J Biomed Nanotechnol. 2007;3(2):203-208.

34. Klueh U, Wagner V, Kelly S, Johnson A, Bryers JD. Efficacy of silvercoated fabric to prevent bacterial colonization and subsequent devicebased biofilm formation. J Biomed Mater Res. 2000;53(6):621-631.

35. Fayaz AM, Balaji K, Girilal M, Yadav R, Kalaichelvan PT, Venketesan R. Biogenic synthesis of silver nanoparticles and their synergistic effect with antibiotics: a study against gram-positive and gram-negative bacteria. Nanomedicine. 2010;6(1):103-109.

36. Li P, Li J, Wu C, Wu Q, Li J. Synergistic antibacterial effects of $\beta$-lactam antibiotic combined with silver nanoparticles. Nanotechnology. 2005;16(9):1912-1917.

37. Abbas HK, Weaver MA, Horn BW, Carbone I, Monacell JT, Shier WT. Selection of Aspergillus flavus isolates for biological control of aflatoxins in corn. Toxin Rev. 2011;30(2-3):59-70.

38. Johnson TR, Case CL. Laboratory Experiments in Microbiology. 9th ed. San Francisco, CA: Benjamin-Cummings Publishing Company; 2010.

39. Mulvaney P. Surface plasmon spectroscopy of nanosized metal particles. Langmuir. 1996;12(3):788-800.

40. Sukhov NL, Ershov NB, Mikhalko VK, Gordeev AV. Absorption spectra of large colloidal silver particles in aqueous solution. Russian Chemical Bulletin. 1997;46(1):197-199.

41. Birla SS, Tiwari VV, Gade AK, Ingle AP, Yadav AP, Rai MK. Fabrication of silver nanoparticles by Phoma glomerata and its combined effect against Escherichia coli, Pseudomonas aeruginosa and Staphylococcus aureus. Lett Appl Microbiol. 2009;48(2):173-179.

42. Chaudhari PR, Masurkar SA, Shidore VB, Kamble SP. Antimicrobial activity of extracellularly synthesized silver nanoparticles using Lactobacillus species obtained from VIZYLAC capsule. Journal of Applied Pharmaceutical Science. 2012;2(3):25-29.

43. Sondi I, Salopek-Sondi B. Silver nanoparticles as antimicrobial agent: a case study on E. coli as a model for Gram-negative bacteria. J Colloid Interface Sci. 2004;275(1):177-182.

44. Davies RL, Etris SF. The development and functions of silver in water purification and disease control. Catalysis Today. 1997;36(1): 107-114.

45. Yamanaka M, Hara K, Kudo J. Bactericidal actions of a silver ion solution on Escherichia coli, studied by energy-filtering transmission electron microscopy and proteomic analysis. Appl Environ Microbiol. 2005;71(11):7589-7593.
International Journal of Nanomedicine

\section{Publish your work in this journal}

The International Journal of Nanomedicine is an international, peerreviewed journal focusing on the application of nanotechnology in diagnostics, therapeutics, and drug delivery systems throughout the biomedical field. This journal is indexed on PubMed Central,

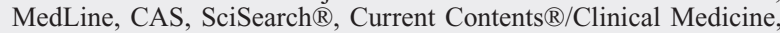

\section{Dovepress}

Journal Citation Reports/Science Edition, EMBase, Scopus and the Elsevier Bibliographic databases. The manuscript management system is completely online and includes a very quick and fair peer-review system, which is all easy to use. Visit http://www.dovepress.com/ testimonials.php to read real quotes from published authors. 